\title{
CAPITAL SOCIAL E DESENVOLVIMENTO SUSTENTAVEL: O CASO DO RIO SURUÍ EM MAGÉ
}

\author{
Emmanoel de Oliveira Boff ${ }^{*}$ \\ Mariana Fleischhauer Corrêa da Costa**
}

enviado: julio 2015 - aceptado: septiembre 2015

\begin{abstract}
Resumo
O capital social pode ajudar a induzir um padrão de desenvolvimento sustentável? Pode-se aferir se e quanto um aumento no capital social está correlacionado à predisposição em conservar um bem público ambiental? Estas são as perguntas que o artigo visa responder com um estudo de caso realizado com 566 moradores do entorno do rio suruí, em Magé, na Baixada Fluminense, no primeiro semestre de 2011. Através de regressões por MQO (mínimos quadrados ordinários) e uma regressão quantílica, esta investigação mostra que há correlação positiva entre o capital social, a renda dos entrevistados e a DAP (disposição a pagar) para conservar o rio Suruí. O trabalho mostra ainda como a DAP pode ser aferida de forma indireta, com base nos dias de trabalhos que o entrevistado estaria disposto a dar para ajudar a conservar o rio, realizando regressão específica para este caso.

Código JEL: H41, Q25, Q56.

Palavras chave: Capital social, disposição a pagar, desenvolvimento sustentável, valoração ambiental.
\end{abstract}

\begin{abstract}
*Universidade Federal Fluminense - emmanoelb@gmail.com

**Universidade Federal Fluminense - Mariana.fleischhauer@yahoo.de
\end{abstract}

Could social capital help induce sustainable development? Is it possible to assess if and how much an increase in social capital is correlated with the predisposition 
to preserve an environmental public good? These are the questions that this paper seeks to answer with a study conducted with 566 residents surrounding the river Suruí in Magé, in Baixada Fluminense, in the first half of 2011. Through OLS (Ordinary Least Squares) and quantile regressions, this research shows that there is a positive correlation between social capital, the income of the residents and WTP (Willingness To Pay) to preserve the river Suruí. The work also shows how WTP can be measured indirectly, based on days of work that the respondent would be willing to give to help save the river, performing a specific regression to this case.

JEL Code: H41, Q25, Q56.

Keywords: Social Capital, willingness to pay, sustainable development, environmental valuation.

\section{INTRODUÇÃO}

As preocupações recentes com a possibilidade de mudanças climáticas e o aumento do "déficit ecológico" global ${ }^{1}$ apontam para a necessidade de uma mudança na relação das atividades humanas com o meio-ambiente. Estas mudanças envolvem tanto a necessidade de diminuir o "transumo" (throughput) per capita quanto à necessidade de manejar recursos naturais com menor impacto em termos de geração de poluentes e degradação de recursos. De que forma as relações que as pessoas cultivam entre si e as instituições de que participam podem intervir nesta mudança? De que forma políticas públicas que incentivem a formação de certos tipos de relações interpessoais e instituições podem auxiliar neste processo de mudança?

O presente trabalho visa lançar alguma luz sobre as questões acima. A hipótese que baliza a pesquisa é de que a rede de relações e de instituições de que as pessoas participam pode ter impacto positivo na conservação/restauração de bens ambientais. Para comprovar esta hipótese, foi realizado um trabalho empírico no entorno do rio Suruí, em Magé, região da Baixada Fluminense. Através de questionários semi-abertos, 600 moradores foram entrevistados com o objetivo de se mensurar a freqüência e o tipo de atividade social que realizavam, bem como sua escolaridade, emprego, renda e o fato de ser morador da região de Suruí. De posse destes dados, dois objetivos foram cumpridos: 1. Medir o capital social da

1 Definido como a diferença entre a biocapacidade do planeta e a pegada ecológica da população do planeta. 
comunidade que vive no entorno e utiliza o rio Suruí, em Magé; e 2. Através de uma regressão linear múltipla, verificar a correlação do capital social, da renda e do fato de ser morador de Suruí na valoração monetária que a população local e freqüentadores fazem do rio Suruí.

O fundamento para testar a hipótese de que o capital social teria algum impacto sobre a disposição em conservar o rio Suruí se dá pelo fato de os bens ambientais terem caráter público. Desta forma, uma comunidade onde as relações sociais sejam variadas e densas pode influir na decisão dos indivíduos com relação à conservação do bem ambiental. Os mecanismos através dos quais esta influência pode ser transmitida são: 1.a partilha de informações; 2. diminuição nos custos de transação e 3. a redução de dilemas de ação coletiva (Isham et al, 2002).

Resta ainda elaborar um modelo teórico preciso que preveja como o capital social, através dos mecanismos acima, pode impactar causalmente a DAP dos agentes. Para fins deste artigo, tal modelo teórico ainda não foi desenvolvido, já que o próprio conceito de capital social é controverso na literatura (como a seção 5 mostrará). O mesmo se sucede com o conceito de desenvolvimento sustentável. Desta forma, optou-se, neste trabalho, por se realizar um estudo exclusivamente empírico. Os eventuais resultados empíricos positivos podem embasar a formulação de um instrumental teórico específico que mostre como o capital social (entendido dentro do arcabouço de uma teoria das redes) pode aumentar a disposição a pagar dos indivíduos para conservar um determinado bem público ou ambiental.

Deste modo, o trabalho será dividido em 7 seções (incluindo esta Introdução e a Conclusão). A $2^{\mathrm{a}}$ seção trata dos métodos de valoração ambiental e da literatura recente que trata da maneira como as relações interpessoais e instituições podem afetar a tomada de decisões individuais. A seção 3 demonstra com mais detalhamento os objetivos da pesquisa, bem como suas diversas fases. A seção 4 explicita a metodologia de pesquisa e aponta como ela foi realizada, indicando a forma do modelo de MQO utilizada na pesquisa. A seção 5 conceitua capital social e desenvolvimento sustentável para fins deste artigo, explicando também qual a relação entre os dois que justifica o artigo. A seção 6 apresenta os dados sobre capital social na região de Suruí e realiza 6 regressões pelo método dos MQO com o fim de mostrar como o capital social e outras variáveis podem influenciar a DAP pelo rio Suruí. Por fim, a seção 7 conclui o artigo. 


\section{FUNDAMENTAÇÃO TEÓRICA E QUALIFICAÇÃO DO PRINCIPAL PROBLEMA ABORDADO}

Em projetos que envolvem valoração ambiental de bens públicos (como florestas, rios ou praias) é comum o uso de métodos indiretos e diretos para aferir o valor econômico total ${ }^{2}$ dos bens ambientais. No caso do uso de métodos indiretos, o valor do recurso é inferido a partir da observação do comportamento do indivíduo em mercados para aquele recurso (Ortiz, 2003: 84-5). Já os métodos diretos de valoração tentam extrair as preferências dos indivíduos com relação ao bem através de questionários aplicados à população-alvo. Entre os métodos diretos, encontra-se o método de valoração contingente (MVC), do qual os métodos de Disposição a Pagar (DAP) e Disposição a Aceitar (DAA) são variantes. O MVC consiste na formulação de perguntas que tentam captar o quanto o indivíduo estaria disposto a pagar para preservar e/ou recuperar o recurso investigado (caso do DAP) ou para aceitar ter o recurso não preservado (caso da DAA). Ou seja, o questionário procuraria extrair as preferências dos habitantes de uma região, visando mostrar a quantidade monetária que os usuários dos recursos estariam dispostos a pagar para preservar/recuperar o bem ambiental. Desta forma, torna-se possível balizar políticas públicas de preservação ambiental de posse do conhecimento sobre as preferências dos agentes afetados pelo bem.

Embora aparentemente simples, a aplicação de tal método pode gerar questionamentos tanto do ponto de vista metodológico quanto do ponto de vista da teoria econômica recente. Seroa da Motta (1998: 47-53) aponta que pesquisas com questionários podem apresentar vieses e incertezas quanto aos seus resultados, tanto do ponto de vista de sua confiabilidade (isto é, quanto ao fato de os estimadores achados serem não-viesados e de mínima variância) quanto de sua validade (isto é, em que grau o estimador reflete o valor monetário "verdadeiro" do recurso).

Recentemente, a idéia de que as preferências dos indivíduos independem das suas relações sociais e do contexto institucional em que eles tomam suas decisões também vêm sendo questionada por alguns autores. Bardsley (2010) faz um apanhado sobre experimentos com bens públicos (como o public goods game), mostrando como a contribuição para o bem público pode possuir motivação pró-social, como a manipulação da identidade do grupo e punição para os freeriders. Bowles $(1998,2004)$ e, mais recentemente Bowles e Gintis (2010) também

2 Denomina-se "valor econômico total" do recurso natural o valor de uso do recurso (que inclui o uso direto, indireto e valor de opção) e valor de existência. Mais sobre o "valor econômico total" na parte de metodologia do trabalho. 
apontam para o modo como as preferências podem ser endógenas aos meios institucionais em que os indivíduos se encontram. Deste modo, o comportamento pró-social pode ser incentivado dependendo da estrutura institucional em que os indivíduos se encontram e do tipo de relação social de que participam. Geoffrey Hodgson (2004) é outro autor que procura mostrar como o comportamento individual pode se influenciado por convenções que se baseiam em atos de outros indivíduos. A recente ganhadora do prêmio Nobel de 2009, Elinor Ostrom (1993) também trabalhou com a questão de como diferentes estruturas institucionais geram incentivos de forma a resolver problemas de ação coletiva - como, por exemplo, conservar um rio.

Todos estes autores, de diferentes maneiras, vêm enfatizando a importância das relações sociais e do contexto institucional na formação das preferências dos agentes e na tomada de decisão individual. Eles apontam que arranjos institucionais diferentes podem gerar preferências e escolhas diferentes dos indivíduos. No caso específico dos recursos naturais, a DAP dos indivíduos pode ser afetada pela educação, pela renda e pelo modo que os indivíduos se organizam em suas relações sociais. A investigação sobre o capital social permite quantificar e qualificar estas relações sociais, bem como as instituições que os indivíduos participam, podendo verificar em que medida elas afetam a DAP por um bem ambiental. ${ }^{3}$

\section{OBJETIVOS DA PESQUISA}

O principal objetivo do trabalho era identificar a influência do capital social, da renda, da educação e do fato de ser morador do distrito de Suruí sobre a DAP dos indivíduos, quantificando monetariamente o impacto destes fatores na DAP dos moradores do distrito de Suruí, em Magé. O trabalho pretendeu verificar se (e em que medida) o aumento de anos de estudo, da renda e do capital social impactam na DAP da população suruiense. Ou seja, o trabalho verificou, na sua

3 Não há um consenso quanto a uma definição de "instituição" na teoria econômica. Uma definição técnica pode ser dada pela "forma extensiva de um jogo exato jogado pelos agentes" (ver Acemoglu, 2007: 10). Para os efeitos deste1 trabalho, podemos seguir a definição de Hodgson (2006: 18), de que instituições "são sistemas de regras sociais estabelecidas e enraizadas que estruturam as relações sociais". Deste modo, aqueles que frequentaram a escolaformal e possuem emprego com carteira assinada tomaram contato com um sistema de regras estabelecido distinto daqueles que não tiveram contato com a escola e não possuem emprego formal. Desta forma, supõe-se que as relações sociais estruturadas pelos que possuem escolaridade e emprego formal são distintas daqueles que não possuem. De acordo com a hipótese levantada neste projeto, estas diferentes estruturas de relação social também gerarão diferentes preferências e decisões quanto à DAP por um recurso natural. 
conclusão, em quantos reais os anos de estudo, a renda, o capital social e o fato de ser morador da região aumentam a DAP dos habitantes da região estudada.

Se conseguirmos quantificar e qualificar as relações interpessoais, bem como o nível de confiança que as pessoas têm umas nas outras, poderemos testar econometricamente em que medida o capital social se relaciona à DAP dos freqüentadores do rio Suruí.

A pesquisa realizada por este trabalho foi cumprida em sete fases: A primeira fase consistiu na elaboração e teste dos questionários. Esta fase foi concluída em janeiro de 2008 quando foram aplicados 40 questionários preliminares aos membros da população em torno do rio Suruí. Devido à baixa escolaridade dos moradores da região de Suruí, houve problemas de interpretação das perguntas, o que nos levou a produzir um segundo modelo de questionário com perguntas mais simples e precisas, na linguagem adequada à população local.

A segunda fase consistiu na identificação do tamanho da amostra ideal que representasse com $97,5 \%$ de confiança a população de Suruí. Para que este cálculo estatístico fosse realizado, foi necessário o estabelecimento de indicadores estatísticos representativos baseados em uma amostra preliminar de 160 entrevistas (já com os novos questionários corrigidos ${ }^{4}$ ) com os moradores de Suruí, realizadas em fevereiro de 2008. Nesta fase identificou-se a necessidade de se entrevistar 600 moradores da região, para atingir o grau de confiança estabelecido 5 .

$\mathrm{Na}$ fase seguinte, foram realizadas 600 entrevistas com a meta explícita de encontrar a DAP dos indivíduos da região estudada. Nesta fase foram computados a escolaridade, a renda, o fato de ser morador de Suruí e o capital social. O capital social aferido teve por base sete perguntas do questionário que quantificaram a ligação entre os moradores e frequentadores da região, bem como as instituições de que participam e a relação com a região (por exemplo, se o indivíduo participa de festas, eventos religiosos, culturais ou esportivos nas proximidades do rio Suruí).

4 Devido à especificidade da pesquisa, consideramos que, por se tratar de um rio, um bem público. Decidimos acrescentar uma pergunta referente ao grau de relação dos indivíduos com o rio. O grau de relação com o rio foi agregado ou não à DAP do indivíduo.

5 Na amostra inicial de 160 entrevistados, identificou-se uma DAP média de R\$ 66, 19, com desvio padrão de R $\$ 108,50$. Se quisermos um erro de $\mathrm{R} \$ 10,00$ com relação à média verdadeira da DAP da população de Suruí (isto é podendo ser de R\$ 56,19 até R\$ 76,19), com 97,5\% de confiança, precisaremos ter cerca de 600 entrevistas, de acordo com a fórmula: número de entrevistas $=(\mathrm{Zx}$ desvio-padrão/Erro)2. Ver Bussab e Morettin 2002. 
A quarta fase do trabalho constituiu o tratamento dos dados encontrados. $\mathrm{O}$ tratamento envolveu a tabulação dos dados, a eliminação de erros devido a prováveis correlações entre as variáveis explicativas e a eliminação de eventuais outliers.

$\mathrm{Na}$ quinta fase foi construído um modelo econométrico, através de regressão múltipla, que mostrou em que medida as variáveis explicativas (renda, escolaridade, capital social e o fato de ser morador) influíram na DAP do indivíduo. Encontraram-se estimativas sobre os impactos da renda, da escolaridade, do capital social e o do fato de ser morador na DAP dos indivíduos.

\section{METODOLOGIA DA PESQUISA}

Como foi colocado na seção 2 , há métodos diretos e indiretos de valoração ambiental. Vamos explicitar melhor agora onde se encontra o método de valoração da DAP para entender as vantagens de sua aplicação para o rio Suruí. Dentre os métodos indiretos, o método de DAP apresenta riscos quanto à sua confiabilidade, viabilidade e vieses. No entanto, apresenta uma série de vantagens em sua aplicação. De forma geral, pode-se dizer que o valor econômico total de um recurso natural pode ser decomposto em quatro subitens (ver Motta, 1998: 27):

1. Valor de uso direto (dado pela exploração e consumo direto do recurso),

2. Valor de uso indireto (necessários para a realização de outras atividades econômicas, como o uso do oxigênio do ar, da água e de recursos genéticos);

3. Valor de opção, referente ao valor de uso direto e indireto dos bens que poderão ser consumidos ou explorados no futuro; e finalmente

4. Valor de não-uso (ou valor de existência), não referente a uso direto ou indireto, hoje ou no futuro, mas a valores éticos ou altruístas na preservação do recurso.

Embora passível de vários vieses, o método de DAP é o único que pode fornecer estimativa do valor de existência do recurso (Ortiz, 2005: 95), daí seu interesse em usá-lo nesta pesquisa.

Poderíamos tentar alcançar os objetivos propostos através do método DAA, no entanto, ele se apresenta como um método enviesado. Quanto ao uso do método DAP frente ao DAA, observa-se que o uso do método DAP diminui o "viés hipotético" de confiabilidade, ou seja, diminui o risco de os valores obtidos não refletirem as verdadeiras preferências (Motta, 1998: 49). Isto ocorre devido ao 
fato de os entrevistados estarem mais familiarizados com o fato de gastar recursos do que de receberem compensações.

A metodologia foi baseada na aplicação de questionários semi-abertos estruturados com dois tipos de perguntas: aquelas que caracterizam o perfil do entrevistado, ou seja, perguntas sobre a renda, escolaridade, emprego formal e capital social, e a pergunta-chave do questionário, que identifica a DAP do indivíduo. Este dado é obtido pela quantidade monetária de dinheiro que o indivíduo estaria disposto a pagar para preservar o rio. Uma novidade deste trabalho está em não se perguntar diretamente ao entrevistado a sua DAP, mas quantos dias da semana ele deixaria de trabalhar para ajudar a recuperar e preservar o rio Suruí. No tratamento dos dados, identificaremos o valor da DAP como fração do salário mensal relatado.

O objetivo de se adotar este novo procedimento é evitar problemas comuns na forma de elicitação do valor que o indivíduo estaria disposto a pagar. Normalmente, as pesquisas sobre valoração ambiental fazem uso de lances livres (quando se pergunta diretamente ao entrevistado o quanto ele estaria disposto a pagar) ou referendo (quando se pergunta diretamente ao entrevistado se ele estaria disposto a pagar certa quantidade pelo recurso). Como aponta Seroa da Motta (1998: 45), o problema com estes métodos é induzir respostas no entrevistado ("viés da obediência") ou negar outros valores oferecidos depois do primeiro lance, por achar que o primeiro valor é o correto ("viés do ponto de partida"). Quando se pergunta ao entrevistado quantos dias ele deixaria de trabalhar por mês para ajudar a limpar o rio, pode-se aferir indiretamente o valor que ele estaria disposto a pagar para conservá-lo, sem os vieses mencionados.

Cabe ainda esclarecimento quanto ao cálculo do índice do capital social dos moradores e freqüentadores da região de Suruí entrevistados para a pesquisa. As perguntas envolviam tanto a freqüência de atividades que as pessoas realizam em grupo na região de Suruí (festas, igrejas, clubes, jogos), quanto atividades que estariam dispostas a realizar em conjunto com outras para ajudar a conservar o rio. No questionário elaborado a escala de capital social variou de - 2 (o indivíduo degrada o rio de alguma forma com freqüência, não participa de nenhuma associação ou grupo na região de Suruí, nem confia ou tem relacionamentos com quem quer que viva em suas proximidades) até 33 (o indivíduo usa o rio com freqüência sem degradá-lo, há participação em todas as associações listadas no questionário, além de plena confiança e relacionamentos recorrentes com todos que vivem nas suas proximidades). 
De onde vem o valor de capital social inicial igual a -2 ? A explicação se encontra no conceito especial de capital social adotado neste trabalho: em vez de valorar apenas as relações dos indivíduos entre si e as instituições de que participam, considerou-se importante valorar também a relação do indivíduo com o rio. Em outras palavras, atribuiu-se um valor ao fato de o indivíduo usar o rio para alguma atividade, com certa freqüência (como tomar banho, pescar, passear, observar o rio ou até mesmo poluir e degradá-lo, jogando lixo, por exemplo). Neste último caso, retirou-se pontos do capital social do entrevistado, já que sua postura prática não leva à preservação do rio.

De que forma se pode justificar tal alteração no conceito de capital social para nosso estudo? A intuição por trás desta inclusão da relação do indivíduo com o rio é que, para que seus efeitos sejam plenos, o capital social deve pertencer aos membros do grupo da região onde se encontra o bem ambiental em questão. $\mathrm{Ou}$ seja, é mais provável que um indivíduo com alto nível de capital social o aplique na conservação dos bens ambientais com que tenha contato mais freqüente. Exemplificando: é mais provável que um morador de Suruí aplique seu capital social na conservação do rio Suruí, e não na conservação do rio Amazonas - muito embora, do ponto de vista ecológico, a conservação do último possa ser mais importante. E, de fato, como os resultados das tabelas 4 e 5 da seção 6 deixarão claro, há uma clara relação empírica entre a aplicação do capital social e o fato de ser morador da região de Suruí. Deste modo, pareceu prudente que alguma relação específica com o rio Suruí contasse pontos para o capital social do entrevistado: a relação com o rio mostra que o entrevistado pode ter algum interesse em aplicar seu capital social na conservação do rio.

Deve-se atentar ainda ao fato de que esta mudança no conceito de capital social não confunde as variáveis “capital social" e "morador" da região de Suruí. É possível que um morador da região de Suruí não se utilize do rio, enquanto que um não-morador freqüente o rio constantemente para pescar, por exemplo. Neste caso, faz sentido imaginar que o não- morador possui maior disposição para utilizar seu capital social para conservar o rio que o morador da região que não usa o rio.

Os questionários foram aplicados por seis entrevistadores especialmente treinados e contratados para a realização da pesquisa, sendo moradores ou trabalhadores da região de Suruí. Visto que as perguntas continham informações sobre a renda e escolaridade das pessoas, existe a tendência de que o entrevistado sinta-se constrangido por ser abordado por um desconhecido, e assim, seja impreciso ou responda de uma forma que ele considere mais conveniente para o entrevistador. Em outras palavras, ele responde o que acha que o entrevistador quer 
ouvir, mesmo que a resposta não seja verdadeira. Por isso, foi prudente a utilização de membros da própria comunidade na aplicação dos questionários. Isto evitou os constrangimentos nas respostas das pessoas que gerariam possíveis vieses nos dados coletados. Essa visão foi utilizada na aplicação dos 40 questionários da primeira fase e dos 160 questionários da segunda fase do trabalho, tentando, desta forma, evitar o "viés do entrevistador e do entrevistado" (Motta, 1998: 49).

Para que a fase da elaboração do modelo econométrico pudesse ser realizada com maior confiabilidade, foi necessário que a amostra de entrevistas utilizadas fosse representativa da população de Suruí. Desta forma, os 160 questionários elaborados na segunda fase serviram como fundamento para a identificação do número de questionários a serem aplicados. Ou seja, os 160 questionários forneceram a média e desvio-padrão amostrais que foram utilizados para cálculo do número de questionários da amostra final, de forma que os dados obtidos na amostra tivessem $97,5 \%$ de confiabilidade, ou seja, refletiram qual seria a DAP da população do distrito de Suruí, em Magé, com 97,5\% de certeza, de acordo com o que foi mostrado na nota de rodapé 5 .

Depois de aplicados os questionários, foi utilizado modelo de regressão por mínimos quadrados ordinários que teve o seguinte formato:

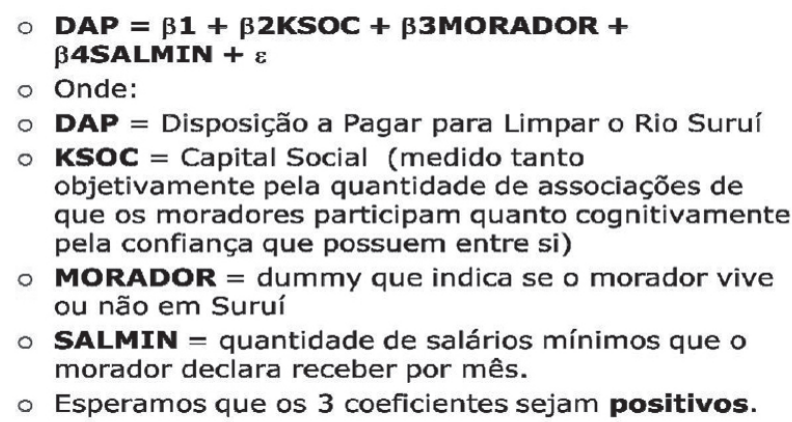

Supõe-se que as variáveis explicativas obedeçam a um comportamento linear em relação ao DAP, daí a elaboração de um modelo de regressão múltipla linear, como o exposto acima. No entanto, durante a fase de tratamento dos dados (fase 4 do trabalho), pode-se identificar que o comportamento de algumas dessas variáveis não é linear, e desta forma, o modelo deverá ser alterado de acordo. Se houvesse, ainda, correlação entre as variáveis explicativas (no nosso caso, é possível que a escolaridade e a renda estejam fortemente correlacionadas) deveríamos tomar medidas de correção do modelo (ver Gujarati, 1995: 338-43). 
Deve-se observar que não existe fórmula definida para especificar a função da DAP individual, de modo que o pesquisador pode enfatizar aquelas variáveis explicativas que quer investigar - no nosso caso, variáveis relativas ao capital social, ao rendimento e ao fato de ser morador do local. De qualquer maneira, especificamente no que tange à influência institucional da educação na DAP, a fórmula segue os trabalhos já realizados por Brugnaro (2002), Silva (2003) e Mattos (2006, 2007). Estes trabalhos não verificaram impacto significativo da educação na DAP dos agentes, o que também foi confirmado em nosso estudo veja a tabela 3 da seção 6 do trabalho.

Ou seja, o trabalho apresenta duas contribuições científicas específicas na área da economia ambiental: a primeira é tentar extrair preferências dos indivíduos pelo método DAP sem o uso de referendo ou lances livres; e a segunda é mensurar o impacto do capital social dos moradores e freqüentadores do entorno do rio Suruí na DAP para a conservação do rio. Do ponto de vista da economia aplicada, o trabalho contribui para a verificação empírica do impacto das variáveis independentes supracitadas na decisão do agente em fornecer recursos financeiros (tanto na forma de dinheiro como em dias de trabalho) para conservar o rio Suruí.

Esta novidade está explícita na escolha das variáveis explicativas da função da DAP. Deste modo, o trabalho está alinhado com os desenvolvimentos teóricos recentes na área da economia institucional aplicada, como foi sublinhado na seção 2 .

\section{O CAPITAL SOCIAL E O DESENVOLVIMENTO SUSTENTÁVEL: DEFINIÇÕES USADAS PARA ESTE TRABALHO ${ }^{6}$}

Antes de podermos verificar os resultados da pesquisa, precisamos definir com precisão, como colocado na Introdução, o que é o capital social e o desenvolvimento sustentável para fins desta pesquisa. Este esclarecimento é essencial, haja vista que os termos capital social e desenvolvimento sustentável não possuem uma definição única na literatura. ${ }^{7}$ As subseções 5.1, 5.2 e 5,3 tratarão,

6 Pode-se questionar a forma como as redes sociais virtuais na Internet aumentam o capital social dos indivíduos. Neste nosso estudo específico, foram desprezadas as influências de redes sociais presentes na Internet, dado que o projeto trata da relação dos moradores ou freqüentadores com um território específico, o rio Suruí. A localização física, neste caso, foi relevante para a pesquisa. Isto significa que os contatos virtuais dos moradores têm pouca possibilidade de alterar sua valoração do rio.

7 São conhecidas as críticas as conceito de desenvolvimento sustentável proposto no Relatório Bruntland ("Our Common Future"): carece de precisão afirmar que as atividades da presente geração não podem comprometer o bem-estar das gerações futuras. O mesmo ocorre com o conceito de capital social, que 
respectivamente, da definição de capital social, da definição de desenvolvimento sustentável e da possível relação entre ambos.

\section{IV.1. CAPITAL SOCIAL}

O capital social refere-se aos recursos que os indivíduos são capazes de obter em virtude de suas relações com outras pessoas, tais como informações, idéias e apoios, e às práticas sociais, normas e relações de confiança que existem entre cidadãos de uma determinada sociedade localizada no espaço e no tempo. A estrutura de uma rede de capital social baseia-se em quem se relaciona com quem, com que freqüência e em que termos, e tem um papel fundamental no fluxo de recursos que circula através dela. Dessa forma as pessoas mais bem relacionadas ocupam posições estratégicas. Aqueles cujas ligações percorrem vários grupos, potencialmente têm mais recursos do que seus pares, já que a posição no interior da rede lhes proporciona maior acesso a mais e melhores recursos. Quanto maior a capacidade dos cidadãos confiarem uns nos outros, e quanto maior e mais rico for o número de possibilidades associativas numa sociedade, maior o volume de capital social.

O capital social representa o potencial de um grupo de indivíduos para construir e manter redes sociais de maneira com que essa organização gere melhorias no bem-estar social, favorecendo o funcionamento de normas e sanções consentidas, ressaltando os interesses públicos coletivos, dos quais o meio ambiente faz parte. Uma melhor organização social poderia contrabalançar uma maior degradação ambiental.

A maneira como os indivíduos se relacionam, portanto, também é um fator de desenvolvimento econômico, tomado em um sentido amplo. Deste modo, é possível traçar um mapa da vida associativa da comunidade e com isso buscar soluções para um conjunto de problemas sociais. Por exemplo, como criminalidade, saúde, pobreza e desemprego têm sido empiricamente associados à existência ou inexistência de capital social em uma comunidade? Este é um dos pontos em que a pesquisa com capital social pode ser útil.

No entanto, Fine (2010, cap. 2) aponta que o conceito de capital social, por ser muito amplo, acaba se tornando um conceito que explica resultados pouco usuais, como a incidência de cáries no Brasil (Pattusi, 2006 apud Fine, 2010). Mais precisamente, a crítica de Fine aponta para o fato de que a suposta relação

foi objeto de críticas recentes por Fine (2010). Analisaremos brevemente estas críticas nesta seção. 
causal entre o capital social e uma determinada conseqüência (p. ex., o capital social causaria uma queda no nível de criminalidade de uma região ou queda no índice de repetência dos alunos em uma escola) é atravessada por outras relações causais (como, p. ex., a qualidade da polícia de uma comunidade ou o grau de escolaridade dos pais de bons alunos). Segundo Fine, teóricos do capital social acabam englobando os demais fatores explicativos sob o termo capital social, transformando-o em um "conceito guarda-chuva", que pode influir sobre qualquer variável de caráter social (como saúde pública, educação, cultura, segurança etc.). Desta forma, não se pode afirmar exatamente qual a relação causal específica entre um determinado resultado e o capital social, haja vista que o conceito pode ser generalizado para influir em uma gama indeterminada de possíveis resultados.

Mas isto por acaso significaria que o conceito de capital social carece de qualquer possibilidade de uso científico? Nan Lin (2008, cap. 1) defende a idéia de que o capital social deva ser compreendido com base em uma teoria das redes. Depois de fazer um apanhado das diversas críticas e imprecisões dos conceitos tradicionais de capital social de Robert Putnam e James Coleman, Nan Lin defende a idéia de que é possível especificar um conceito de capital social tendo por base as redes das quais os membros de uma determinada comunidade, em um determinado território e período de tempo fazem parte. Nesta conceituação de capital social, os indivíduos seriam os "nós" da rede, enquanto os laços que eles possuem entre si podem ser fortes ou fracos, além de poderem constituir redes mais ou menos densas (ver Grannoveter 1983).

Esta definição mais precisa de capital social pode servir de base para que, por exemplo, se possa verificar em que medida um determinado tipo de rede permite resolver um problema de ação coletiva com relação a um recurso comum. Pode também mostrar como a partilha de informações em determinada rede permite punir aqueles que degradam um recurso comum (por exemplo, aqueles que poluem um rio). Crê-se que, a partir do uso da teoria das redes, seja possível constituir um arcabouço que possa mostrar relações causais entre os diversos tipos de rede e o desempenho de certas comunidades estudadas com relação a algumas variáveis sociais, como aquelas exemplificadas nos parágrafos acima.

Para este trabalho, não foi elaborado este tipo de teoria. Deste modo, tudo que podemos apresentar com os resultados são correlações entre as variáveis estudadas. Para fins deste artigo usamos a classificação de capital social em duas dimensões de van Bastelaer e Grootaaert (2002): a dimensão objetiva (relativa à densidade e número de associações e grupos formais entre os indivíduos de uma determinada área geográfica) e a dimensão cognitiva (relativa aos valores, normas 
e crenças partilhados pelos indivíduos). O conceito que usamos supõe ainda que interações sociais padronizadas e recorrentes dentro de uma determinada área geográfica bem definida - o entorno do rio Suruí -- formam uma estrutura social específica. As características desta estrutura social poderão afetar muitas decisões econômicas dos agentes dentro daquela área, como foi colocado na introdução.

\section{IV.2. DESENVOLVIMENTO SUSTENTÁVEL}

Como podemos definir desenvolvimento sustentável de forma precisa? Para nossos objetivos, definimos desenvolvimento sustentável como aquele baseado em três dimensões:

1. Para ser sustentável o desenvolvimento deve ser socialmente justo;

2. Deve ser também economicamente viável;

3. E, por fim, deve ser ecologicamente sustentável.

Esta definição está em acordo com aquela proposta na Agenda 21, delineada na Rio Eco - 92. Vale observar que os três pés do desenvolvimento sustentável estão inter-relacionados. Ou seja, o desenvolvimento é dito sustentável apenas se estiver sobre estes três "pés" concomitantemente. De qualquer forma, devemos precisar ainda mais cada um dos termos deste tripé. Ou seja, o modo de organização das comunidades humanas em sua relação com o meio-ambiente para manter e reproduzir sua existência deve, simultaneamente:

1. Garantir justiça na distribuição do produto e dos serviços públicos (não deve haver situação generalizada e constante de penúria ou insegurança a qualquer grupo social);

2. Garantir retorno adequado (isto é, suficiente para cobrir custos de oportunidade) àqueles que investem na produção;

3. Garantir que o meio-ambiente não se degrade a ponto de o bem-estar das próximas gerações ficar comprometido vis-à-vis o bem-estar da geração atual. Em outras palavras, o saldo ecológico dessas comunidades, no longo prazo, deve ser positivo ou igual a zero.

Embora tenhamos tentado dar maior precisão aos conceitos de "capital social" e "desenvolvimento sustentável", deve-se notar que tais termos são apenas relativamente mais precisos. Isto ocorre porque conceitos como "justiça", "bem-estar" de uma geração e "retorno adequado" dependem de uma determinada visão de mundo e da especificidade histórica e cultural dos grupamentos humanos. Desta forma, do ponto 
de vista adotado neste artigo, é inevitável a adoção de uma visão de mundo específica que nos diga o que se entende por "justiça", "bem-estar" e "retorno adequado" antes de iniciar uma pesquisa com base no desenvolvimento sustentável ${ }^{8}$.

Também deve se atentar para as inter-relações entre as três dimensões da sustentabilidade. Por exemplo, se determinada sociedade consegue gerar um rendimento médio para seus membros de forma a retirar virtualmente todos os seus membros de situações de risco de penúria e insegurança, ela ainda não pode ser considerada sustentável. Isto porque, se seu saldo ecológico for negativo, ela esgotará os recursos do seu território (ou esgotará os recursos do território de outrem) e tal fato minará seu desenvolvimento ao longo do tempo.

Do mesmo modo, se outra sociedade distribui mal os recursos gerados a seus membros, produzindo grande desigualdade (apesar de hipoteticamente sua renda média ser elevada e de ter saldo ecológico positivo), ela não pode ser considerada sustentável. Isto porque quanto maior a desigualdade, maior a tendência a tensões sociais e à possibilidade de perdas de eficiência econômica devido à desigualdade, como recentes estudos mostram (ver Blyth e Hopkin 2008, como exemplo). No longo prazo, desta forma, uma desigualdade (seja na renda, nos riscos sociais ou no acesso a bens públicos) tende igualmente a minar o desenvolvimento.

Um último exemplo diz respeito ao lado econômico do tripé: uma sociedade cuja desigualdade não seja elevada e que possui balanço ecológico positivo provavelmente também não será sustentável se não prover incentivos adequados à produção. Sem um retorno adequado de seus esforços (lembrando sempre que a idéia de "retorno adequado" é relativa a uma determinada escala de valores histórica e culturalmente dada), o nível de produção não deve se manter no longo prazo.

Dado este sentido triplo ao conceito de desenvolvimento sustentável, cabe verificar como, para fins deste artigo, podemos relacioná-lo ao conceito de capital social.

8 Isto está de acordo com a visão de Gunnar Myrdal (1976) com relação à objetividade das ciências sociais. 


\section{IV.3. COMO RELACIONAR DESENVOLVIMENTO SUSTENTÁVEL E CAPITAL SOCIAL?}

Um dos objetivos deste trabalho é verificar em que medida o capital social pode se relacionar ao desenvolvimento sustentável. Desta forma, dadas as definições acima, temos que mostrar como poderemos relacionar um ao outro.

Observamos acima que os bens ambientais possuem caráter público. Deste modo, para se conservar bens públicos e usá-los de modo sustentável, é útil que aqueles que usam o rio, partilhem de informações e sejam capazes de resolver problemas de coordenação da ação coletiva. Por exemplo, se a informação for partilhada por grande parte dos freqüentadores e moradores da região de Suruí, serão menores os custos de transação para a punição daqueles que degradam o rio. Da mesma forma, se um conjunto de pescadores possui confiança uns nos outros, é mais fácil promover a coordenação de todos para o uso racional da pesca no local. Por fim, se houver algum problema de poluição do rio por parte de alguma indústria, moradores mais bem relacionados e com acesso às instituições de justiça conseguirão acionar as instâncias públicas responsáveis para que tomem providências quanto ao problema.

Os exemplos acima atestam para uma possível relação entre ao menos um dos "pés" do desenvolvimento sustentável (a conservação e manejo não-destrutivo do meio-ambiente) e o nível de capital social de uma determinada região (pois o capital social pode auxiliar na resolução de problemas de ação coletiva que dificultariam o uso eficiente do recurso). Como os três "pés" do desenvolvimento sustentável estão inter-relacionados, é possível afirmar que o capital social e o desenvolvimento sustentável também estejam, desta forma, correlacionados. No nosso caso específico, esta relação deve dar-se entre a DAP para conservar o bem-ambiental e o capital social dos moradores da região.

\section{ANALISE DOS RESULTADOS}

Abaixo mostramos a tabela 1, que indica a média e o desvio-padrão das variáveis relevantes para nosso estudo. Temos seis médias e seis desvios-padrões, haja vista que o entorno do rio Suruí foi dividido em seis subregiões, para que toda sua extensão fosse coberta. Ou seja, foram entrevistados 100 moradores em cada região, somando 600 entrevistas, como foi colocado na metodologia. Como a região do entorno do rio possui população uniformemente distribuída (informação colhida junto à ONG Água Doce Serviços Populares, que trabalha na região), não 
foi necessário entrevistar números diferentes de indivíduos em cada uma das 6 subregiões.

Tabela 1. Médias e Desvios Padrões das Variáveis Investigadas nas 6 sub-regiões Estudadas no entorno do Rio Suruí ${ }^{9}$

\begin{tabular}{|c|c|c|c|c|c|c|}
\hline Regiões & $\begin{array}{l}\text { Capital } \\
\text { Social }\end{array}$ & Escolaridade & $\begin{array}{l}\text { Salário } \\
\text { mínimo }\end{array}$ & Morador & $\begin{array}{c}\text { Dias de } \\
\text { trabalho } \\
\text { que daria } \\
\text { para } \\
\text { limpar o } \\
\text { rio }\end{array}$ & $\begin{array}{c}\text { Valor } \\
\text { que daria } \\
\text { para } \\
\text { limpar o } \\
\text { rio }(\mathrm{R} \$)\end{array}$ \\
\hline 1 & 8,49 & 2,21 & 1,98 & 0,95 & 0,74 & 25,37 \\
\hline 1 & 3,70 & 1,37 & 1,16 & 0,22 & 1,10 & 58,45 \\
\hline 2 & 11,74 & 1,98 & 1,56 & 1,00 & 0,68 & 7,70 \\
\hline 2 & 2,40 & 0,99 & 0,55 & 0,30 & 0,48 & 8,76 \\
\hline 3 & 9,79 & 2,24 & 1,37 & 0,90 & 0,71 & 14,12 \\
\hline 3 & 3,55 & 1,49 & 0,79 & 0,28 & 0,61 & 16,39 \\
\hline 4 & 10,19 & 1,82 & 1,44 & 0,98 & 0,80 & 24,38 \\
\hline 4 & 4,16 & 1,30 & 0,68 & 0,14 & 0,93 & 87,68 \\
\hline 5 & 9,46 & 1,87 & 1,65 & 0,99 & 1,21 & 23,68 \\
\hline 5 & 3,72 & 1,60 & 1,25 & 0,10 & 4,16 & 73,47 \\
\hline 6 & 12,67 & 2,72 & 2,22 & 1,00 & 1,22 & 29,17 \\
\hline 6 & 4,05 & 1,68 & 1,82 & 0,00 & 0,62 & 56,30 \\
\hline $\begin{array}{l}\text { Total } \\
\text { Média }\end{array}$ & 10,37 & 2,14 & 1,70 & 0,83 & 0,90 & 20,85 \\
\hline \multicolumn{7}{|l|}{ Total } \\
\hline $\begin{array}{l}\text { Desvio } \\
\text { Padrão }\end{array}$ & 3,92 & 1,46 & 1,17 & 0,37 & 1,89 & 58,37 \\
\hline
\end{tabular}

9 Foi feita uma escala para a variável Escolaridade que abrange os valores 0 (nenhuma escolaridade), 1 (ensino fundamental incompleto), 2 (ensino fundamental completo), 3 (ensino médio incompleto), 4 (ensino médio completo), 5 (ensino superior incompleto), até 6 (curso superior completo). 
Um primeiro ponto de interesse é observar que na $2^{\mathrm{a}}$ região estudada o valor fornecido para ajudar a limpar o rio foi muito mais baixo que nas outras regiões $(\mathrm{R} \$ 7,70)$. Este valor tem forte correlação com o fato de ser morador da região de Suruí, tendo o coeficiente de correlação de Pearson (r) valor 0,833 entre essas duas variáveis. No nosso estudo, os entrevistados da região 2 consistiam principalmente em pessoas que freqüentam o rio Suruí a passeio ou que simplesmente atravessam a região, não residindo no local.

Esperou-se também que houvesse forte correlação entre o salário dos dias de trabalho que o entrevistado daria para limpar o rio e o valor monetário relatado que ofereceria para o mesmo propósito. Contudo, a correlação entre essas duas variáveis foi apenas moderada $(\mathrm{r}=0,649)$. Este fato leva a crer que há, provavelmente, um problema de "enquadramento" (framing) das perguntas. Ou seja, embora a resposta à pergunta sobre a quantidade de dias de salário mensal devesse, em princípio, ter forte correlação com o valor da DAP dado monetariamente, não foi o que se observou na prática. Como o salário médio recebido dos entrevistados à época da pesquisa foi de $\mathrm{R} \$ 926,50$ e o número de dias médios relatados que dariam para limpar o rio foi de 0,90 , pode-se mostrar que o valor estimado médio em dias de trabalho que dariam para limpar o rio seria de $\mathrm{R} \$ 37,90$ (salário mínimo da época $(\mathrm{R} \$ 545$ x 0.90)/22 dias trabalhados por mês, em média), contra o valor monetário médio oferecido de $\mathrm{R} \$ 20,85 \mathrm{com}$ a resposta livre. Ou seja, a média dos dias oferecidos para limpar o rio foi cerca de $81,79 \%$ mais alta que a média do valor monetário oferecido. Logo, os valores mostram que, em princípio, as pessoas teriam uma disposição maior em abrir mão do seu salário para limpar o rio do que dar o dinheiro com esse fim.

Esta diferença entre os valores monetários e os dias de trabalho oferecidos também terão impacto na regressão a ser realizada, como a tabela 4, na seção 6 , explicitará.

Por fim, pode-se observar que o desvio-padrão de algumas DAPs é elevado, em algumas regiões. Este valor elevado ocorre pela presença de alguns outliers, quando entrevistados chegaram a afirmar que dariam para o rio Suruí mais do que sua própria renda mensal. Nestes casos, os valores foram retirados para que não houvesse distorção dos resultados - já que, na prática, é pouco provável que tais indivíduos dessem efetivamente esta quantidade de recursos para a conservação do rio.

A seguir mostraremos o resultado de algumas regressões realizadas, de forma a comprovar se há relação efetiva entre o capital social e a disposição a 
pagar pela conservação do rio Suruí. DAPs acima de R \$ 200 foram excluídas para não gerar distorções nos resultados.

Tabela 2. Mínimos Quadrados Ordinários (MQO), usando as observações 1-566 (das 600 entrevistas, 34 foram excluídas por conter falhas no preenchimento dos questionários ou valores de DAP incompatíveis com o rendimento do pesquisado)

Variável dependente: Valor que daria para limpar o rio

\begin{tabular}{lccccc}
\hline & Coeficiente & $\begin{array}{c}\text { Erro } \\
\text { Padrão }\end{array}$ & razão-t & p-valor & \\
\hline constante & $-7,26003$ & 3,08053 & $-2,3567$ & 0,01878 & $* *$ \\
Capital_Social & 0,779216 & 0,20705 & 3,7634 & 0,00019 & $* * *$ \\
Morador & 5,95514 & 2,11248 & 2,8190 & 0,00499 & $* * *$ \\
Salario_minimo & 4,8313 & 0,682721 & 7,0765 & $<0,00001$ & $* * *$ \\
\hline
\end{tabular}

Média var. dependente Soma resíd. quadrados R-quadrado $\mathrm{F}(3,562)$

Log da verossimilhança Critério de Schwarz

13,94876
196982,9
0,127976
27,49251
$-2459,314$
4943,982

D.P. var. dependente

19,99520 18,72173 0,123321 $1,33 \mathrm{e}-16$ 4926,628 4933,401

Como esperado, todos os coeficientes da regressão foram positivos e significativos (i.e. estão correlacionados positivamente com a DAP pela conservação do rio Suruí). O R-quadrado ajustado foi de cerca de 0,12 , significando que as variáveis independentes escolhidas explicam cerca de $12 \%$ da variabilidade da DAP para conservar o rio.

O coeficiente para o capital social foi de aproximadamente 0,78 , ou seja, o aumento de uma unidade no capital social do entrevistado está relacionado a um aumento de $\mathrm{R} \$ 0,78$, em média, na DAP do indivíduo. Como em nossa investigação a média do capital social encontrada foi de 10,37, há um grande potencial para aumentar o capital social da região - lembremos que nosso índice de capital social compreende o intervalo de -2 até 33. Em outras palavras, um aumento no nível de capital social dos moradores e freqüentadores do rio possivelmente aumentaria também a valoração monetária do rio Suruí expressa pela DAP. 
Outro aspecto da pesquisa buscou verificar se diversos níveis de educação ${ }^{10}$ impactariam positivamente na DAP dos moradores.

A tabela 3 abaixo mostra, como as pesquisas já mencionadas na seção 4, que o nível de educação, em nenhum dos seus níveis, possui impacto significativo na formação da DAP para conservar o rio Suruí limpo. Inicialmente, esperou-se que houvesse uma correlação significativa e positiva entre a instituição da escola e a DAP - ou seja, mais escolaridade provavelmente se traduziria em maior consciência ambiental e, possivelmente, em uma maior propensão em ajudar a conservar o meio-ambiente. Pode-se especular que tal correlação não tenha sido observada tendo por base a constatação de que não há atividades educacionais especificamente voltadas para a importância da preservação do meio-ambiente entre as escolas da região. Desta forma, ir à escola não faria diferença na importância atribuída à conservação do rio. No entanto, tal especulação carece de embasamento empírico.

Tabela 3. MQO, usando as observações 1-566

Variável dependente: Valor_que_daria para limpar o rio

\begin{tabular}{lccccc}
\hline & Coeficiente & Erro Padrão & razão-t & \multicolumn{2}{c}{$p$-valor } \\
\hline constante & $-7,58343$ & 3,24366 & $-2,3379$ & 0,01974 & $* *$ \\
Morador & 6,00755 & 2,1585 & 2,7832 & 0,00556 & $* * *$ \\
Capital_Social & 0,792924 & 0,207708 & 3,8175 & 0,00015 & $* * *$ \\
Ensino_Funda- & $-0,399412$ & 1,92854 & $-0,2071$ & 0,83600 & \\
mental & & & & & \\
Ensino_Medio & 0,352277 & 2,29089 & 0,1538 & 0,87784 & \\
Ensino_Superior & $-6,46748$ & 5,14429 & $-1,2572$ & 0,20920 & \\
Salario_minimo & 5,0918 & 0,71965 & 7,0754 & $<0,00001$ & $* * *$ \\
\hline
\end{tabular}

Média var. dependente

Soma resíd. quadrados

R-quadrado

$\mathrm{F}(6,559)$

Log da verossimilhança

Critério de Schwarz
13,94876

196388,9

0,130605

13,99602

$-2458,459$

4961,289
D.P. var. dependente

E.P. da regressão

19,99520

R-quadrado ajustado

P-valor(F)

Critério de Akaike

Critério Hannan-Quinn
18,74358

0,121274

$7,25 \mathrm{e}-15$

4930,918

4942,772

10 Foram inseridas dummies para ensino fundamental (possui ensino fundamental $=1$; não possui $=$ 0 ), sendo o mesmo feito com ensino médio e ensino superior 
Verifiquemos agora como se comportam as variáveis se perguntarmos sobre o valor mensal (em dias de trabalho) que o entrevistado daria para conservar o rio Suruí.

Tabela 4. MQO, usando as observações 1-566

Variável dependente: Dias_de_trabalho que daria para conservar o rio Suruí

\begin{tabular}{lccccc}
\hline & Coeficiente & Erro Padrão & razão-t & p-valor & \\
\hline constante & 0,255578 & 0,119324 & 2,1419 & 0,03263 & $* *$ \\
Salario_minimo & 0,0170479 & 0,0264452 & 0,6447 & 0,51942 & \\
Capital_Social & 0,0342407 & 0,00802006 & 4,2694 & 0,00002 & $* * *$ \\
Morador & 0,166116 & 0,0818269 & 2,0301 & 0,04282 & $* *$ \\
\hline
\end{tabular}

Média var. dependente

Soma resíd. quadrados

R-quadrado

$\mathrm{F}(3,562)$

Log da verossimilhança

Critério de Schwarz
0,776502

295,5523

0,038784

7,558678

$-619,2404$

1263,835
D.P. var. dependente

E.P. da regressão

R-quadrado ajustado

P-valor(F)

Critério de Akaike

Critério Hannan-Quinn
0,737704

0,725185

0,033653

0,000058

1246,481

1253,254

Neste caso observa-se que os coeficientes para morador da região e o capital social continuam a ser significativos, mas o rendimento do morador deixa de sê-lo. Ou seja, os dados apontam que a disposição em conservar o rio não-monetariamente (isto é, em dias de trabalho) não tem relação com o rendimento do entrevistado. Observa-se também que o R-quadrado ajustado, que mede a variabilidade da DAP que pode ser efetivamente explicada pelas variáveis independentes do modelo adquire valor bastante baixo $(0,03)$, cerca de quatro vezes menor que aquele encontrado nos outros modelos $(0,12)$.

Verificamos em nossa pesquisa ainda que havia regiões cujos freqüentadores do rio Suruí não eram moradores da área - a mesma região que, na Tabela 1, teve a menor DAP. Podemos investigar o que ocorreria com a influência do capital social e do rendimento na DAP caso selecionássemos apenas estes casos, comparando-os, posteriormente, com os moradores de Suruí. De fato, mesmo que os freqüentadores (em contraste com os moradores) da região do rio Suruí possuam capital social elevado, nada garante que este capital social esteja, de algum modo, associado ao território onde se encontra o rio Suruí. A regressão abaixo confirma tal hipótese: 
Tabela 5. MQO, usando as observações 1-96 - não-moradores da região de Suruí, com exceção de valores da DAP incompatíveis com o rendimento do entrevistado

Variável dependente: Valor_que_daria para conservar o rio

\begin{tabular}{lcccc}
\hline & Coeficiente & Erro Padrão & razão-t & p-valor \\
\hline constante & 0,587072 & 4,80075 & 0,1223 & 0,90294 \\
Salario_minimo & 6,65544 & 1,55285 & 4,2859 & $0,00004 \quad * * *$ \\
Capital_Social & $-0,179756$ & 0,389039 & $-0,4620$ & 0,64512 \\
\hline
\end{tabular}

Houve um pequeno aumento do R-quadrado ajustado (para 0,15) e o capital social deixou de ser significativo - na verdade, o coeficiente observado é Média var. dependente

9,572917

D.P. var. dependente

11,29671

Soma resíd. quadrados

10114,19

E.P. da regressão

10,42855

R-quadrado

0,165736

R-quadrado ajustado

0,147795

$\mathrm{F}(2,93)$

9,237763

P-valor(F)

0,000219

Log da verossimilhança

$-359,7707$

Critério de Akaike

725,5415

Critério de Schwarz

733,2345

Critério Hannan-Quinn

728,6511

até negativo. Este dado sugere que uma relação de proximidade com o rio Suruí parece ser determinante para que o capital social tenha impacto na sua conservação. Em outros termos: não basta ter capital social elevado para estar disposto a cuidar do rio; é central que este capital social pertença aos moradores da região. De qualquer forma, o coeficiente relativo ao rendimento do entrevistado mostrou ser significativo e o mais alto de todos os modelos testados. Em outras palavras, para não-moradores, a renda possui grande correlação com a DAP pela conservação do rio. Vejamos, agora, o que ocorre se tomarmos apenas os moradores de Suruí: 
Tabela 6. MQO, usando as observações 1-470

- apenas moradores do entorno do rio

Suruí Variável dependente: Valor_que_daria para conservar o rio

\begin{tabular}{lccccc}
\hline & Coeficiente & Erro Padrão & razão-t & p-valor & \\
\hline constante & $-2,01779$ & 2,6288 & $-0,7676$ & 0,44313 & \\
Salario_minimo & 4,70647 & 0,750827 & 6,2684 & $<0,00001$ & $* * *$ \\
Capital_Social & 0,870574 & 0,231168 & 3,7660 & 0,00019 & $* * *$ \\
\hline
\end{tabular}

Média var. dependente

Soma resíd. quadrados

R-quadrado

$\mathrm{F}(2,467)$

Log da verossimilhança

Critério de Schwarz
14,84255

186082,8

0,120402

31,96218

$-2072,486$

4163,431
D.P. var. dependente

E.P. da regressão

R-quadrado ajustado

P-valor(F)

Critério de Akaike

Critério Hannan-Quinn
21,23854

19,96157

0,116635

$9,78 \mathrm{e}-14$

4150,973

4155,874

Neste caso o impacto do capital social sobre a DAP volta a ser significativo, com valor cerca de $\mathrm{R} \$ 0,10$ mais alto que aquele observado para a amostra total. Deste modo, percebemos que o resultado intuitivo esperado sobre a correlação da moradia na região do rio Suruí com a DAP é empiricamente comprovado. O mesmo resultado também pode ser obtido se multiplicarmos a variável "morador" (que é uma dummy) pela variável "capital social". Desta forma, também comprovamos o efeito de ser morador na DAP pelo rio.

Por fim, podemos testar como cada uma das variáveis independentes do modelo se relaciona com cada quartil da amostra. Assim veremos como os coeficientes se comportam à medida que aumenta a DAP. Para tal, precisaremos trabalhar com uma regressão quantílica, como veremos na tabela a seguir: 
Tabela 7. Estimativas dos quantis, usando as observações 1-470

Variável dependente: Valor_que_daria para conservar o rio

Erros padrão assintóticos assumindo erros IID

Omitido devido a colinearidade exata: Morador

\begin{tabular}{lllll}
\hline & tau & coeficiente & erro padrão & razão-t \\
\hline constante & 0,250 & $-1,39706$ & 0,870281 & $-1,60530$ \\
& 0,500 & 1,66667 & 1,39774 & 1,19240 \\
& 0,750 & 1,17647 & 2,90094 & 0,405549 \\
Salário_minimo & 0,250 & 0,588235 & 0,248566 & 2,36652 \\
& 0,500 & 1,66667 & 0,399218 & 4,17483 \\
& 0,750 & 7,05882 & 0,828553 & 8,51946 \\
Capital_Social & 0,250 & 0,367647 & 0,0765294 & 4,80400 \\
& 0,500 & 0,416667 & 0,122913 & 3,38994 \\
& 0,750 & 0,588235 & 0,255098 & 2,30592
\end{tabular}

Mediana var.

dependente $\quad 10,00000$

D.P. var.

dependente $\quad 21,23854$

A tabela acima indica que os coeficientes das variáveis "salário mínimo" e "capital social" são ambos significativos para todos os quartis estudados. O interessante a se notar é que o valor dos coeficientes destas variáveis cresce mais rapidamente a cada quartil. Veja, por exemplo, que a correlação do capital social com a DAP é de apenas 0,36 no primeiro quartil (significando que apenas $\mathrm{R} \$ 0,36$, em média, são agregados à DAP para um aumento de uma unidade no capital social); sobe para 0,41 na mediana, e depois 0,58 no $3^{\circ}$ quartil. Isto significa que há uma correlação entre DAPs maiores e coeficientes maiores de capital social. Em outras palavras, o capital social sempre impacta positivamente a DAP, mas este impacto cresce à medida que a DAP cresce. Com o rendimento a velocidade de crescimento é ainda mais veloz: o aumento de um salário mínimo para o primeiro quartil leva apenas a um aumento de R\$ 0,58 na DAP. Quando se chega ao $3^{\circ}$ quartil este valor mais que decuplica, chegando a $\mathrm{R} \$ 7,05$. 


\section{CONCLUSÃO}

O artigo teve como objetivos medir o capital social dos moradores da região de Suruí e verificar em que medida ele estava correlacionado com a DAP pela conservação do rio. Uma primeira novidade do trabalho, portanto, refere-se à mensuração do capital social dos moradores do entorno do rio Suruí e do teste de sua possível correlação com a DAP. Chegou-se como resultado a um nível de capital social baixo para a região (10,37, com um valor máximo de 33). Verificou-se que o capital social correlaciona-se positivamente com a DAP para conservar o rio, o mesmo ocorrendo com a renda do entrevistado e o fato de ser morador da região de Suruí. A educação não mostrou correlação com a DAP dos entrevistados.

Outra novidade do artigo foi tentar aferir a DAP através dos dias de salário dados pelo entrevistado para conservar o rio. Este valor foi mais elevado que aquele dado pela DAP monetária (mais de $81 \%$ maior) e tem uma correlação moderada com esta mesma DAP - esperava-se uma correlação mais alta, inicialmente. Ou seja, é provável que o modo como se coloca a questão influencie a resposta do entrevistado. Neste caso, o capital social e o fato de ser morador de Suruí continuaram correlacionados à DAP do entrevistado, mas o rendimento do entrevistado deixou de ter esta correlação.

Outro ponto de interesse é verificar que, ao menos no caso de Suruí, não basta ter capital social elevado para que ele se correlacione à DAP. O fato de ser morador da área é central para que essa correlação se verifique. Ou seja, a aplicação do capital social para a conservação do bem em questão está correlacionada ao território onde o bem ambiental se encontra.

Quanto aos futuros desdobramentos do trabalho, os dados coletados nos permitem ainda perguntar o que ocorreria com a DAP se a população tivesse um nível maior de capital social, de renda e de escolaridade. Já que a população apresentou nível baixo nível de capital social e que a renda pode aumentar com o aumento da escolaridade dos moradores, pode-se, por exemplo, criar um índice teórico ideal, chamado "Índice Potencial" de crescimento da DAP. Este índice pode comparar a DAP realmente aferida com uma DAP ideal que podemos denominar "DAP cidadã". Esta última refletirá a DAP ideal de uma população cujos membros possuem, em grande parte, nível superior de ensino, renda compatível com este nível de escolaridade e elevado capital social. Assim, podemos definir o "Índice Potencial" do seguinte modo:

$$
I P=\frac{D A D_{\text {Real }}}{D A D_{\text {Cidada }}}
$$


Donde $0<\mathrm{IP}<1 ; \mathrm{IP}=$ Índice Potencial; DAP real = DAP média efetivamente aferida; e DAP cidadã = DAP média ideal, com a população possuindo nível de escolaridade elevado (com renda compatível com este nível de escolaridade) e alto nível de capital social.

Este índice teórico servirá para mostrar o potencial aumento da DAP real aferida frente a tendências futuras de aumentos na renda, escolaridade e no capital social. Ou seja, se o IP estiver próximo de zero, isto significa que o desenvolvimento da população face às variáveis relacionadas é baixo e que há um potencial para crescimento da DAP real. Por outro lado, se o IP estiver próximo de um, isto significa que a população já apresenta elevado desenvolvimento das variáveis mencionadas (em última instância, as instituições educacionais, rendimento e capital social podem estar influenciando a DAP da população ribeirinha em maior grau). Isto é, pode-se estimar que a DAP real subirá nos anos subseqüentes à realização da pesquisa tendo por base o crescimento da renda per capita da região, do índice de escolaridade e do capital social, aproximando-se, desta forma, da "DAP cidadã" ideal. A regressão quantílica realizada mostra que maiores DAPs estão associadas a maiores coeficientes das variáveis "capital social" e "salário mínimo". Deste modo, aumentos no capital social e no rendimento tendem a aproximar a DAP real da DAP cidadã mais rapidamente.

Do ponto de vista empírico, o interesse de criação desse índice potencial está em mostrar como variáveis sociais e institucionais - como a escolaridade (e o nível médio de renda maior a ela associado) e o capital social - estão correlacionadas às preferências individuais (neste caso, a DAP dos entrevistados no rio Suruí). Embora até o momento puramente empírica, esta pesquisa se encontra em diálogo com os avanços teóricos recentes apontados na seção 2 , que procuram entender as preferências individuais não mais como dadas, mas moldadas por variáveis institucionais e sociais.

Do ponto de vista aplicado, tal índice pode fornecer ao poder públicas informações que mostrem em que medida a valoração de bens ambientais está correlacionada a variáveis como o capital social e a renda. Neste caso, um eventual valor baixo da DAP real da população de uma determinada região com relação a um bem ambiental específico não poderia ser tomado simplesmente como dado: deve-se levar em conta como esta DAP muda em relação a uma população que, idealmente, valoraria o bem de modo distinto, por possuir escolaridade, capital social e rendimentos mais elevados. Embora pequeno para um dado indivíduo (haja vista que o coeficiente de capital social é baixo e o R-quadrado ajustado 
também), quando agregado a toda uma população o valor da DAP cidadã pode resultar muito maior. Pode-se sugerir que, para fins de política pública ambiental, os valores da DAP real sejam comparados com a DAP cidadã ideal, para que se tenha uma idéia de como certo bem seria valorado, caso a população possuísse níveis de renda, escolaridade e capital social ideais.

\section{BIBLIOGRAFIA}

Acemoglu, D.,\& Robinson, J. (2007). Lecture Notes for Political Economy of Institutions and Development. Recuperado de http://web.mit.edu/14.773/ www/2003\%20Class\%20notes.pdf

Bardsley, N. (2010) Interpersonal Interaction and Economic Theory: The Case of Public Goods. In B. Gui, \& R. Sugden, (Eds.). Economics and Social Interaction: Accounting for Interpersonal Relations. (pp.76-104). New York: Cambridge University Press.

Blyth, M., \& Hopkin, J. (2008). Equality Versus Efficiency? Structural Reform, Inequality, and Economic Performance in Western Europe. University of Trento, School of International Studies, Working Paper 01. Recuperado de http://web.unitn.it/files/download/9722/wp012008hopkinblyth.pdf

Bowles, S. (1998). Endogenous Preferences: The Cultural Consequences of Markets and Other Economic Institutions. Journal of Economic Literature, 36 (1), (75-111).

Bowles, S. (2004). Microeconomics: Behavior, Institutions and Evolution. Princeton, N.J.: Princeton University Press.

Bowles, S.; Gintis, H. (2011). A Cooperative Species: Human Reciprocity and Its Evolution. Princeton, N. J.: Princeton University Press.

Brugnaro, C. (2002). Valor Atribuído pela População às Matas Ciliares da Bacia do Rio Corumbataí. (Tese de Doutorado em Economia Aplicada). Escola Superior de Agricultura Luiz de Queiroz,: Piracicaba.

Bussab, W. \& Morettin, P.A. (2002). Estatística Básica (5ª edição). São Paulo: Saraiva.

Fine, B. (2010). Theories of Social Capital: Researchers Behaving Badly. New York: Pluto.

Granovetter, M. (1983). The Strength of Weak Ties: A Network Theory Revisited. Sociological Theory, 1, 201-233.

Grootaert, C., \& Van Bastelaer, T. (2002). Understanding and measuring social capital: A synthesis of findings and recommendations from the social capital initiative. The World Bank, Social Development Family, Environmentally and Socially Sustainable Development Network, Working Paper No. 24. 
Recuperado de http://siteresources.worldbank.org/INTSOCIALCAPITAL/

Resources/Social-Capital-Initiative-Working-Paper-Series/SCI-WPS-24.pdf Gujarati, D. N. (1995). Econometria básica (3 edição ). São Paulo: Editora Campus. Hodgson, G. (2006). What are Institutions? Journal of Economic Issues, 40 (1), 1-25. Hodgson, G. \& Knudsen, T. (2004). The complex evolution of a simple traffic convention: the functions and implications of Habit. Journal of Economic Behavior and Organization, 54, pp. 19-47.

Isham, J., Kelly, T., \& Ramaswamy, S. (Eds.) (2002). Social Capital and Economic Development: Well-Being in Developing Countries. New York: Edward Elgar Publishing.

Lin, N., Cook, K. \& Burt, R. S. (Eds.) (2008). Social Capital: Theory and Research. New Jersey: Transaction Publishers.

Lustosa, M. C., May, P. H., \& Vinha, V. (2003). Economia do Meio Ambiente. Rio de Janeiro:Campus.

Mattos, A. D. M., Jacovine, L. A. G., Valverde, S. R., Lopes de Souza, A., Lopes da Silva, M., \& Estáquio de Lima, J. (2006). Valoração Ambiental de áreas de preservação permanente da microbacia do ribeirão São Bartolomeu no Município de Viçosa, (MG). Dissertação de Mestrado. Viçosa: UFV.

Mattos, A. D. M., Jacovine, L. A. G., Valverde, S. R., Lopes de Souza, A., Lopes da Silva, M., \& Estáquio de Lima, J. (2007). Valoração ambiental de áreas de preservação permanente da microbacia do ribeirão São Bartolomeu no Município de Viçosa, MG. Revista Árvore, 31 (2), 347-353.

Mota, R. S. (1998). Manual para a Valoração Econômica de Recursos Ambientais. Brasília: Ed do IPEA.

Myrdal, G. (1976). A Objetividade nas Ciências Sociais. Lisboa: Assírio Alvim.

Ortiz, R. A. (2003). Valoração Econômica ambiental. Em Lustosa, M. C., May, P. H., \& Vinha, V. (2003). Economia do Meio Ambiente. Rio de Janeiro: Campus.

Ostrom, E. et al. (1993). Institutional Incentives and Sustainable Development: Infrastructure Policies in Perspective. Oxford: Westview Press.

Silva. R.G. (2003). Valoração do Parque Ambiental "Chico Mendes" em Rio Branco (AC): Uma Aplicação Probabilística do Método Referendum com Bidding Games. Dissertação de Mestrado. Viçosa: UFV.

(C) 2015 por los autores; licencia otorgada a la Revista Estudios Económicos. Este artículo es de acceso abierto y distribuido bajo los términos y condiciones de una licencia Atribución-No Comercial 3.0 Unported (CC BY-NC 3.0) de Creative Commons. Para ver una copia de esta licencia, visite http://creativecommons.org/ licenses/by-nc/3.0/ 